\title{
Rationale, design and methods for the RIGHT Track Health Study: pathways from childhood self-regulation to cardiovascular risk in adolescence
}

Laurie Wideman ${ }^{*}$, Susan D. Calkins², James A. Janssen ${ }^{1}$, Cheryl A. Lovelady ${ }^{3}$, Jessica M. Dollar ${ }^{2}$, Susan P. Keane ${ }^{4}$, Eliana M. Perrin ${ }^{5}$ and Lilly Shanahan ${ }^{6}$

\begin{abstract}
Background: Cardiovascular risk factors during adolescence-including obesity, elevated lipids, altered glucose metabolism, hypertension, and elevated low-grade inflammation-is cause for serious concern and potentially impacts subsequent morbidity and mortality. Despite the importance of these cardiovascular risk factors, very little is known about their developmental origins in childhood. In addition, since adolescence is a time when individuals are navigating major life changes and gaining increasing autonomy from their parents or parental figures, it is a period when control over their own health behaviors (e.g. drug use, sleep, nutrition) also increases. The primary aim of this paper is to describe the rationale, design and methods for the RIGHT Track Health Study. This study examines self-regulation as a key factor in the development of cardiovascular risk, and further explores health behaviors as an explanatory mechanism of this association. We also examine potential moderators (e.g. psychosocial adversities such as harsh parenting) of this association.

Method/design: RIGHT Track is a longitudinal study that investigates social and emotional development. The RIGHT Track Health Study prospectively follows participants from age 2 through young adulthood in an effort to understand how self-regulatory behavior throughout childhood alters the trajectories of various cardiovascular risk factors during late adolescence via health behaviors. Individuals from RIGHT Track were re-contacted and invited to participate in adolescent data collection ( 16.5, 17.5 and $18^{+}$years old). Individuals completed assessments of body composition, anthropometric indicators, fitness testing (via peak oxygen consumption), heart rate variability during orthostatic challenge, 7-day accelerometry for physical activity and sleep, 24-h dietary recalls, and blood analysis for biomarkers related to metabolic syndrome, inflammatory status and various hormones and cytokines. Individuals also completed extensive self-report measures on diet and eating regulation, physical activity and sedentary behaviors, sleep, substance use, medical history, medication use and a laboratory-day checklist, which chronicled previous day activities and menstrual information for female participants.
\end{abstract}

Discussion: Insights emerging from this analysis can help researchers and public health policy administrators target intervention efforts in early childhood, when preventing chronic disease is most cost-effective and behavior is more malleable.

Keywords: Longitudinal cohort, Childhood self-regulation, Cardiovascular risk factors, Adolescent health behaviors, Diet, Physical activity

\footnotetext{
*Correspondence: I_widema@uncg.edu

'Department of Kinesiology, University of North Carolina Greensboro,

Greensboro 27402, NC, USA

Full list of author information is available at the end of the article
} 


\section{Background}

Obesity is a key risk factor for cardiovascular disease (CVD), and while obesity rates have remained relatively stable in children and adolescents in the past few years $[1,2]$, the obesity and overweight prevalence in adolescents aged $12-19$ is still quite high (17.3\% for obesity (BMI $\geq 95$ th percentile) [1], and $32.2 \%$ for overweight and obesity combined ( $\geq 85$ th percentile) [1]). Overweight and obesity status among young people is often accompanied by increases in other traditional cardiovascular risk factors, such as elevated lipids, altered glucose metabolism, and hypertension [3-9]. Systematic elevations of these factors constitute the metabolic syndrome, which is a robust predictor of morbidity and mortality in later life [10-17]. Alarmingly, estimated rates of metabolic syndrome in adolescents have more than doubled from $4.2 \%$ in the early 90 's to $10.1 \%$ in a more recent study [18]. Although it is not as extensively studied, elevated systemic low-grade inflammation is a correlate of obesity even at young ages [19]. Indeed, it is an independent marker of cardiovascular and metabolic disease risk [10-17, 19-21] and predicts adult CVD independent of metabolic syndrome [22-24]. Such elevated inflammation is relatively stable [25-27] and associated with vascular changes involved in atherosclerosis, which appear to be reversible during the early life course [28-32]. Thus, cardiovascular risk factors during adolescence-including obesity, elevated lipids, altered glucose metabolism, hypertension, and elevated low-grade inflammation-is cause for serious concern. Cardiovascular risk factors initiate and contribute to chronic disease processes and robustly predict subsequent morbidity and mortality by young adulthood or even earlier [33-38]. Despite the importance of these cardiovascular risk factors to health, most are rarely studied during adolescence, and very little is known about their developmental origins in childhood.

Although most research has focused on cardiovascular risk factors beginning in midlife or later, adolescence is emerging as a key period for potential increases in cardiovascular risk. Recent data from representative samples indicate that rates of several cardiovascular risk factors (e.g., hypertension, obesity, elevated low-grade inflammation) rise during adolescence, reaching relatively high levels by young adulthood [12, 18, 25, 39-41], and self-report of perceived health also declines beginning in midadolescence $[42,43]$. In response to these trends, research studies focusing on prevention and intervention have examined and attempted to mitigate several early sources of cardiovascular risk factors; including "obesogenic" environments (neighborhood, home, childcare, school), media influences and other cultural and community factors as well as family factors, such as parental knowledge, attitudes, and modeling [44-47]. This work has contributed to immense progress in this field, and, quite possibly to the leveling off or even declining rates of pediatric obesity in the past 10 years [48-51]. Nevertheless, the prevalence of obesity remains high, offering an enduring impetus for more efficient translation of research-based interventions into professional practice guidelines that reduce obesity.

Research-based interventions with high levels of control for multiple variables are often expensive and burdensome for participants, limiting their utility for large scale dissemination. Ground-breaking new research suggests that deficits in self-regulation (sometimes also referred to as self-control) during childhood could be key to predicting adult disease risk, even when accounting for other risk factors such as poverty or low IQ [52]. Yet virtually no research to date has investigated whether this childhood individual-level risk factor is associated with increases in cardiovascular risk during adolescence and via which mechanisms. Adult chronic disease is concentrated among people who exhibited childhood deficits in self-regulation (SR) [52]. We use the term SR to refer to a specific set of processes or control mechanisms that function at the biological, emotional and behavioral level and enable individuals to manage arousal, attention, emotion, behavior, and cognition in adaptive ways [53-55]. Based on research among adults, both SR and cardiovascular risk factors appear to be associated with health behaviors (e.g., substance use, exercise, nutrition, and sleep). Given that SR emerges early and undergoes substantial development across childhood and into adolescence, an understanding of childhood emotional, behavioral, and physiological precursors to adolescent cardiovascular risk factors would inform and fine-tune prevention and intervention efforts that are aimed at disrupting pathways to adolescent cardiovascular risk, and ultimately at reducing the likelihood of adult CVD. This prospective-longitudinal study tracks changes in cardiovascular risk factors during late adolescence, a time during which parental control decreases dramatically, and SR may become more influential with respect to an individual's health behaviors.

The ability of early SR to predict long-term health outcomes raised new hypotheses (grouped under four larger overall aims stated below) that are tested in the current study (see Fig. 1). To date, a fine-grained study of childhood SR, health behaviors and adolescent cardiovascular risk factors has not been possible due to a lack of extensive longitudinal data and excellent measures of these constructs. The current study utilizes an existing cohort studied from age 2, with extensive, state-of-the-art SR and psychosocial adversity data and collects diverse indicators of cardiovascular risk (traditional and non-traditional), and health behaviors in late adolescence. The specific aims of the study are; 1) to examine pathways from childhood SR to adolescent cardiovascular risk factors; 2) to test 


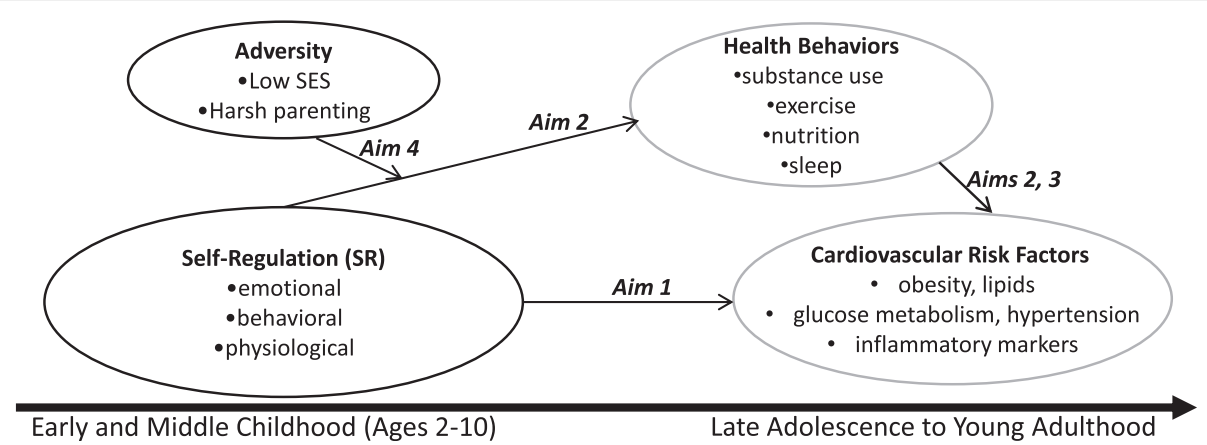

Fig. 1 The potential pathways from childhood self-regulation to adolescent health behaviors and cardiovascular risk tested in the RIGHT Track Health Study. Childhood SR $\rightarrow$ health behaviors $\rightarrow$ adolescent CVR. Grey circles represent new data collection. Black circles represent historic data that are already collected

whether health behaviors mediate the childhood SR to adolescent cardiovascular risk factor pathways; 3) to establish directionality between health behaviors and cardiovascular risk factors and among indicators of cardiovascular risk during adolescence; and; 4) to test whether early SR to adolescent cardiovascular risk associations are moderated by the presence or absence of additional vulnerability factors, such as psychosocial adversity (e.g. poverty, harsh parenting).

\section{Methods/design}

All procedures described in this manuscript have been approved by the University of North Carolina Greensboro Institutional Review Board (\#11-0360; PI Wideman and \#09-0427; PI Calkins) and the University of North Carolina Chapel Hill Institutional Review Board (\#121817; PI: Shanahan). Pilot testing started in Fall 2012 and data collection for the first assessments with the current study protocol began in Spring 2014.

\section{Sample description}

The current study recruits adolescents from three cohorts of individuals who are part of the ongoing, longitudinal study known as RIGHT Track, which investigates social and emotional development. The goal of the original recruitment was to obtain a sample of children who were at risk for developing future externalizing behavior problems and who were representative of the surrounding community in terms of race and socioeconomic status (SES). All cohorts were recruited through child day care centers, the County Health Department, and the local Women, Infants, and Children (WIC) program in central North Carolina (see Fig. 2 for setting). Potential participants for cohorts 1 and 2 were recruited at 2-years of age (cohort 1: 1994-1996 and cohort 2: 2000-2001) and screened using the Child Behavior Checklist (CBCL 2-3) [56], completed by the mother, in order to over-sample for externalizing behavior problems. Children were identified as being at risk for future externalizing behaviors if they received an externalizing T-score of 60 or above. Efforts were made to obtain approximately equal numbers of males and females. This recruitment effort resulted in a total of 307 children. Cohort 3 was initially recruited when infants were 6 months of age (in 1998) for their level of frustration, based on laboratory observation and parent report, and were followed through the toddler period (see Calkins et al. 2002 [57], for more information). Children from Cohort 3 whose mothers completed the $\mathrm{CBCL}$ at 2-years of age $(N=140)$ were then recruited for the larger study. Of the entire sample $(N=447), 37 \%$ of children were identified as being at risk for future externalizing problems. There were no significant demographic differences between cohorts with regard to gender, $X^{2}(2, N=447)=.63$, $p=.73$, race, $\chi^{2}(2, N=447)=1.13, p=.57$, or 2 -year SES, $F$ $(2,444)=.53, p=.59$.

Of the 447 originally selected participants, six were dropped because they did not participate in any data collection at 2 years old. An additional 12 families participated at recruitment, did not participate at the 2-year assessment, but did participate at later years. At 4 years of age, 399 families participated. Families lost to attrition included those who could not be located, moved out of the area, declined participation, or did not respond to phone and letter requests to participate. At age 5 years, 365 families participated, including four who did not participate in the 4-year assessment and at 7 years of age, 350 families participated, including 19 who did not participate in the 5 -year assessment. Families with lower 2-year SES, $t(432)=-2.61, p<.01$, were less likely to participate in the 7-year assessment. At age 10, 357 families participated, including 31 families who did not participate in the 7-year assessment. Independent of previous participation, attempts were made to recruit all families at every time point. Figure 3 provides detailed participation information at each age and statistical comparisons for participants versus non-participants based on key demographic variables. 


\section{The RIGHT Track Health Project}

- 5 waves of psychological and physiological data collection in childhood.

- 2 waves of psychological and physiological data collection in adolescence.

- 3 waves of cardiovascular health and health behaviors data collection in adolescence.

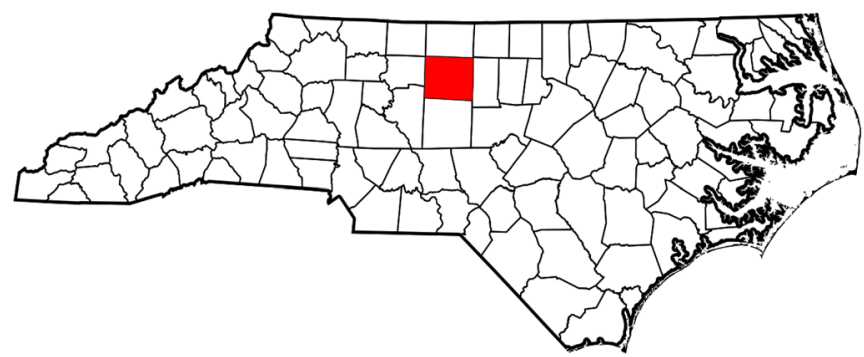

- Setting of original data collection: In Guilford County, North Carolina (NC), United States of America.

- NC falls into the so called "stroke belt" of the US. That is, adults in North Carolina are at increased risk for obesity, cardiovascular disease, elevated Creactive protein compared to adults in other regions of the United States.

Fig. 2 The geographical setting for the RIGHT Track Health Study

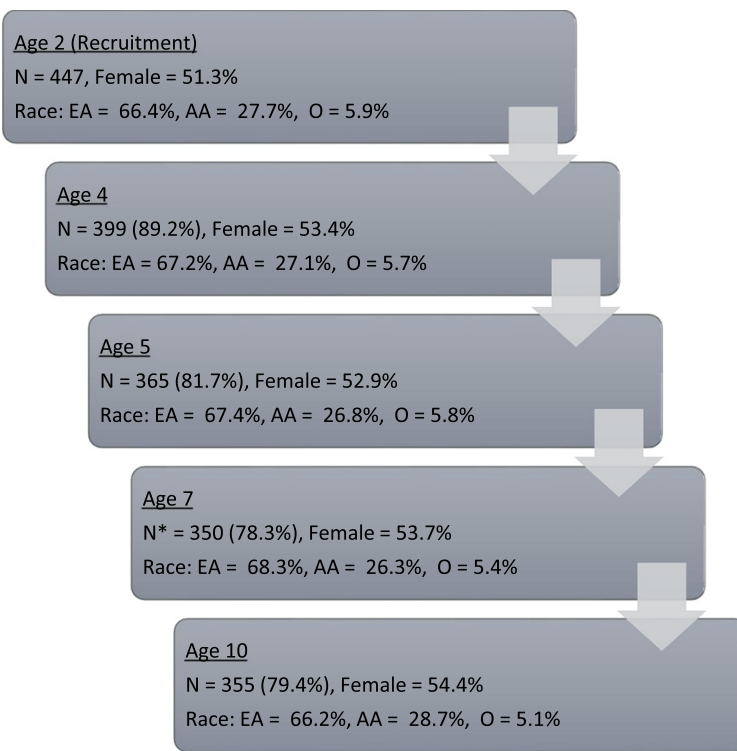

Fig. 3 Sample attrition summary for childhood self-regulation assessments. Unless otherwise noted, there were no significant differences between those who participated at each time point compared to those who did not. As in most longitudinal studies, some participants were involved intermittently, participating at some assessment points, missing others, but then resuming their participation in the study at later time points. * denotes that families with lower 2 years SES were less likely to participate. $\mathrm{EA}=$ European American, $\mathrm{A}=$ African American, $\mathrm{O}=$ Biracial or Other Race
Historic data utilized in the current study

Historic data that were collected as part of the original RIGHT Track longitudinal study [NIMH 55625, NIMH 55584 \& NIMH 58144] will be utilized as predictors in the current study to answer our specific aims. Measures of childhood adversity were collected at various time points throughout childhood (Table 1) and will be used to assess the role of vulnerability factors in predicting cardiovascular risk in adolescence. The following section includes a brief description and key references for other historic variables that will be used in the current study. For a detailed list of manuscripts that have utilized this historic data, please see Additional file 1.

The primary construct of interest from the childhood data is self-regulation. Self-regulation refers to the ability to modulate arousal and behavior in the context of specific environmental demands and these control processes function at the physiological, attentional, emotional, behavioral, cognitive, and social level [55]. Table 2 provides examples of the measures of physiological, emotional, and behavioral regulation that were assessed from ages two through ten. We also provide a more detailed explanation of the assessments of these constructs in the text that follows.

Physiological Self-regulation; Investigations of physiological markers of self-regulation have underscored the importance of the parasympathetic nervous system for regulating cardiac output under conditions of challenge [58]. Specifically, the myelinated vagus nerve, originating in the brainstem nucleus ambiguus, provides input to 
Table 1 Examples of different historic measures of childhood adversity collected as part of the RIGHT Track study, measures at ages $2,4,5,7$, and 10 years old

\begin{tabular}{|c|c|c|c|c|}
\hline Constructs & Example Measures & Example Variable & Reporter & Resources \\
\hline \multirow{2}{*}{$\begin{array}{l}\text { Low } \\
\text { socioeconomic } \\
\text { status }\end{array}$} & Parental education and employment & \multirow[t]{2}{*}{ Hollingshead index } & Mother and father & \multirow[t]{2}{*}{ Hollingshead (1975) } \\
\hline & $\begin{array}{l}\text { Physical aggression, verbal aggression, } \\
\text { discipline strategies, negative control, } \\
\text { punitive reactions }\end{array}$ & & Mother, father, observed & \\
\hline \multirow{6}{*}{$\begin{array}{l}\text { Harsh } \\
\text { parenting }\end{array}$} & \multirow{6}{*}{$\begin{array}{l}\text { Conflict Tactics Scale, lowa Family } \\
\text { Interaction Rating Scales: Instrument, } \\
\text { Alabama Parenting Questionnaire, } \\
\text { Home Observation for Measurement } \\
\text { of the Environment (HOME), Coping } \\
\text { with Children's Negative Emotions } \\
\text { Scale }\end{array}$} & \multirow{6}{*}{$\begin{array}{l}\text { Physical aggression, verbal } \\
\text { aggression, discipline } \\
\text { strategies, negative control, } \\
\text { physical control, punitive } \\
\text { reactions }\end{array}$} & \multirow{6}{*}{$\begin{array}{l}\text { Mother, father, observed } \\
\text { (in laboratory), observed } \\
\text { (in home) }\end{array}$} & Bradley, \& Caldwell (1979) \\
\hline & & & & Straus (1979) \\
\hline & & & & Melby \& Conger (2001) \\
\hline & & & & $\begin{array}{l}\text { Smith, Calkins, Keane, Anastopoulos } \\
\& \text {, Shelton. (2004) }\end{array}$ \\
\hline & & & & Fabes, Eisenberg, \& Bernzweig (1990) \\
\hline & & & & $\begin{array}{l}\text { Fabes, Poulin, Eisenberg, \& Madden- } \\
\text { Derdich (2002). }\end{array}$ \\
\hline
\end{tabular}

Table 2 Example measures of childhood physiological, emotional, and behavioral regulation a ages 2, 4, 5, 7, and 10 years old

\begin{tabular}{|c|c|c|c|c|}
\hline Construct & Example Measures & Example Variables & Reporter & Resources \\
\hline \multirow[t]{5}{*}{$\begin{array}{l}\text { Physiological } \\
\text { regulation }\end{array}$} & \multirow{5}{*}{$\begin{array}{l}\text { Lab-TAB Emotion-eliciting Tasks } \\
\text { (i.e., Transparent Box, Puzzle Box), } \\
\text { Continuous Performace Test (CPT), } \\
\text { Tower Of Hanoi }\end{array}$} & \multirow[t]{5}{*}{$\begin{array}{l}\text { RSA, RSA change, mean heart } \\
\text { period, mean heart rate }\end{array}$} & \multirow[t]{5}{*}{ Observed } & $\begin{array}{l}\text { Goldsmith, Reilly, } \\
\text { Lemery, Longley, } \\
\text { \& Prescott (1993) }\end{array}$ \\
\hline & & & & $\begin{array}{l}\text { Goldsmith \& } \\
\text { Rothbart (2010) }\end{array}$ \\
\hline & & & & $\begin{array}{l}\text { Eisenberg et al. } \\
\text { (2001) }\end{array}$ \\
\hline & & & & Connors (1994) \\
\hline & & & & Simon (1975) \\
\hline \multirow[t]{7}{*}{$\begin{array}{l}\text { Emotional } \\
\text { regulation }\end{array}$} & \multirow{7}{*}{$\begin{array}{l}\text { Child Behavior Questionnaire (CBQ), } \\
\text { Emotion Regulation Checklist (ERC), } \\
\text { Lab-TAB Emotion-eliciting Tasks } \\
\text { (i.e., Transparent Box, Puzzle Box, } \\
\text { toy play/barrier task, perfect circle task), Child Behavioral } \\
\text { Checklist (CBCL), The Behavioral } \\
\text { Assessment System for Children (BASC), } \\
\text { Child Depression Inventory (CDI), } \\
\text { Diagnostic Interview Schedule for } \\
\text { Children (DISC) }\end{array}$} & \multirow{7}{*}{$\begin{array}{l}\text { Negative affectivity, emotion } \\
\text { regulation, distraction, help- } \\
\text { seeking, venting, anger, fear, } \\
\text { soothability, self-comforting, } \\
\text { management of negative } \\
\text { affect, depressive symptoms, } \\
\text { symptoms of anxiety }\end{array}$} & \multirow[t]{7}{*}{$\begin{array}{l}\text { Mother and father, } \\
\text { Teacher, Observed }\end{array}$} & $\begin{array}{l}\text { Putnam \& } \\
\text { Rothbart (2006) }\end{array}$ \\
\hline & & & & $\begin{array}{l}\text { Shields \& } \\
\text { Cicchetti (1997) }\end{array}$ \\
\hline & & & & $\begin{array}{l}\text { See above for } \\
\text { Lab-TAB } \\
\text { citations }\end{array}$ \\
\hline & & & & $\begin{array}{l}\text { Achenbach \& } \\
\text { Rescorla (2001) }\end{array}$ \\
\hline & & & & $\begin{array}{l}\text { Reynolds \& } \\
\text { Kamphaus (2004) }\end{array}$ \\
\hline & & & & Kovacs (1992) \\
\hline & & & & $\begin{array}{l}\text { Shaffer, Fisher, } \\
\text { \& Lucas (1997) }\end{array}$ \\
\hline \multirow[t]{4}{*}{$\begin{array}{l}\text { Behavioral } \\
\text { regulation }\end{array}$} & \multirow[t]{4}{*}{$\begin{array}{l}\text { Snack Delay, Stroop Task, CPT, CBQ, naturalistic interaction, } \\
\text { AD/HD Rating Scale-IV, Disruptive } \\
\text { Behaviors Rating Scale }\end{array}$} & \multirow{4}{*}{$\begin{array}{l}\text { impulsivity, (dis)inhibition, } \\
\text { compliance with instructions, } \\
\text { defiance, self-distraction, } \\
\text { persistence, approach }\end{array}$} & \multirow[t]{4}{*}{$\begin{array}{l}\text { Observed, Mother } \\
\text { and father }\end{array}$} & $\begin{array}{l}\text { Kochanska., } \\
\text { Murray, \& Coy } \\
\text { (1997) }\end{array}$ \\
\hline & & & & $\begin{array}{l}\text { DuPaul, } \\
\text { Anastopoulos, } \\
\text { Power, Murphy, } \\
\text { \& Barkley (1994) }\end{array}$ \\
\hline & & & & $\begin{array}{l}\text { Anastopoulos } \\
\text { (1992) }\end{array}$ \\
\hline & & & & $\begin{array}{l}\text { See above for } \\
\text { CPT, CBQ } \\
\text { citations }\end{array}$ \\
\hline
\end{tabular}


the sinoatrial node of the heart, producing dynamic changes in cardiac activity that allow the organism to transition between sustaining metabolic processes and generating more complex responses to the environment [59]. Of particular interest has been measurement of vagal regulation of the heart (indexed by decreases in respiratory sinus arrhythmia (RSA)) when the organism is challenged. Decreases in RSA when the individual is challenged, or vagal withdrawal, is linked to behavioral processes that are regulatory in nature $[57,60]$.

Physiological regulation procedures. Baseline RSA and RSA change, or vagal withdrawal, were assessed during engagement in developmentally appropriate tasks at each age. Of particular interest to studies of selfregulation is the collection of children's RSA in a baseline task and tasks that elicit frustration.

At the 2-, 4-, and 5-year visits, children watched a 5min segment of a neutral video about a puppy that explores its neighborhood to obtain baseline/resting RSA. At ages 7 and 10, children sat quietly to obtain baseline RSA. Children also participated in an age appropriate frustration/challenge task at each time point (Laboratory Temperament Assessment Battery: Locomotor Version 2.0 ; [61]). At age 2, children were given a toy or cookies in a locked box that they could not open. After $2 \mathrm{~min}$, the experimenter came back in the room and helped the child to get the toy or cookies. At age 4, children were instructed to draw perfect circles and were told repeatedly for $3.5 \mathrm{~min}$ that the circles were not perfect; positive feedback was provided on the last circle drawn. At age 5 , children participated in a task where an experimenter was to divide candy between themselves and the child. The experimenter gave themselves more candy than the child and also took the child's candy and ate it. At ages 7 and 10 years, children participated in both behavioral and cognitive frustration tasks. For example, children put together towers of increasing difficulty, depicted in a picture, and participated in a Stroop colornaming interference task where the child was asked to read words by noting the color the word was printed in and not the word. Children also completed a task at ages 7 and 10, in which the child was presented a puzzle in a large box that was to be completed without looking at it; children could cheat by lifting a cloth that covered the front of the box.

Respiratory Sinus Arrhythmia (RSA). To collect heart rate data, the experimenter placed three disposable pediatric electrodes in an inverted triangle on the child's chest. The electrodes were connected to a preamplifier, the output of which was transmitted to a vagal tone monitor (Ages 2, 4, 5, 7, \& 10 years (cohort 1): VTM-I, Delta Biometrics, Inc., Bethesda, MD; Age 10 cohorts 2 and 3: Biolog 399x; UFI; Morro Bay, CA) for R-wave detection. A data file containing the interbeat intervals
(IBIs) for the period of collection was transferred to a laptop computer for later artifact editing (resulting from child movement) and analysis. At ages 2, 4, 5, 7, and 10 years (cohort 1 ) measures of children's RSA were obtained by editing IBI files using MXEDIT software (Delta Biometrics, Bethesda, MD). Cardio Batch/Edit software (Brain-Body Center, University of Illinois at Chicago, Chicago) was used to edit files for the 10 year visit for cohorts 2 and 3. Both software programs used the Porges (1985) [62] method of analyzing IBI data to calculate RSA. This method applies an algorithm to the sequential heart period (HP) data. The algorithm uses a moving 21-point polynomial to detrend periodicities in heart period that are slower than RSA. Then, a bandpass filter extracts variance in $\mathrm{HP}$ within the frequency band of spontaneous respiration, 0.24-1.04 Hz (ages 2, 4, 5, and 7) or $0.12-1.00 \mathrm{~Hz}$ (age 10). The natural log of this variance is taken and reported in units of $\ln (\mathrm{msec})^{2}$. To edit the files, the data were scanned for outlier points, relative to adjacent data. These outliers were replaced by dividing or summing them so that they would be more consistent with the surrounding data.

RSA was calculated every $30 \mathrm{~s}$ and the average across the 30-s epochs for each task is typically used in analyses. RSA change scores were computed by subtracting the frustration task RSA from baseline RSA [63-65]. Positive change scores reflect a decrease in RSA from baseline to the challenge task indicating RSA withdrawal.

\section{Cardiovascular risk markers}

Late adolescents report to the Exercise Physiology Laboratory at the University of North Carolina Greensboro at approximately ages 16.5 [also called Time 1 visit (T1)], 17.5 [also called Time 2 visit (T2)] and 18 or older [also called Young Adult visit (YA)] for assessment of various cardiovascular risk factors and health behaviors. The study design was chosen to minimize participant burden at the T2 visit, when significant data collection was still occurring for the original RIGHT Track longitudinal study on self-regulatory behaviors. Prior to arrival in the laboratory for the cardiovascular risk marker visit, participants are asked to abstain from vigorous exercise and alcohol consumption for the previous $24 \mathrm{~h}$. In addition, all participants are asked to abstain from smoking the day of testing and to abstain from food for the 2 $\mathrm{h}$ prior to testing [66]. All participants are instructed to maintain adequate hydration in the $24 \mathrm{~h}$ prior to testing and water intake is encouraged prior to this testing session. Immediately prior to the start of the heart rate variability (HRV) data collection at the YA visit, participants are asked to void, since bladder distention has been shown to markedly alter sympathetic activity [67].

Upon arrival at the laboratory, all procedures for the specific visit (as outlined in Table 3), are explained in 
Table 3 Assessment of cardiovascular risk markers and health behaviors in the RIGHT Track health study by time point of the study

\begin{tabular}{|c|c|c|c|}
\hline Construct/Assessment & $\mathrm{T} 1$ & $T 2$ & $Y A$ \\
\hline \multicolumn{4}{|l|}{ Cardivascular Risk Markers } \\
\hline BMI and overweight / obesity status & $x$ & $x$ & $x$ \\
\hline $\begin{array}{l}\text { Anthropomorphic indicators (e.g., } \\
\text { waist circumference, hip circumference, } \\
\text { sagittal abdominal diameter ) }\end{array}$ & $x$ & $x$ & $x$ \\
\hline Blood pressure and pre-/hypertension status & $x$ & $x$ & $x$ \\
\hline Serum markers of metabolic syndrome (e.g., & $x$ & $x$ & $x$ \\
\hline $\begin{array}{l}\text { Serum pro-inflammatory markers (e.g., } \\
\text { C-reactive protein) }\end{array}$ & $x$ & $x$ & $x$ \\
\hline Serum anti-inflammatory markers & $x$ & $x$ & $x$ \\
\hline $\begin{array}{l}\text { Body composition (e.g., body fat, fat mass, } \\
\text { percent body fat) }\end{array}$ & & & $x$ \\
\hline Peak oxygen consumption & & & $x$ \\
\hline $\begin{array}{l}\text { Heart rate variability during exercise and } \\
\text { orthostatic challence }\end{array}$ & & & $x$ \\
\hline $\begin{array}{l}\text { Self-Reported Health Behaviors (e.g., physical } \\
\text { activity, eating behaviors, sleep, substance use) }\end{array}$ & $x$ & $x$ & $x$ \\
\hline \multicolumn{4}{|l|}{ Objectively Assessed Health Behaviors } \\
\hline $\begin{array}{l}\text { 24-h Dietary Recalls (e.g..., Healthy Eating } \\
\text { Index, total fruit and sodium intake, empty calories) }\end{array}$ & $x$ & & $x$ \\
\hline $\begin{array}{l}\text { 7-day Accelerometry (e.g., low intensity, } \\
\text { moderate, vigorous physical activity; sedentary } \\
\text { time; sleep patterns) }\end{array}$ & & & $x$ \\
\hline
\end{tabular}

detail to the parent(s) (at $\mathrm{T} 1$ and $\mathrm{T} 2$ only) and to the adolescent. Consent and assent for the historic RIGHT Track assessments was provided for each set of testing procedures when the procedures occurred; this model of consent and assent is maintained at the $\mathrm{T} 1$ and $\mathrm{T} 2$ visits. At the YA visit, only participant consent is obtained.

Biomarker Collection and Analyses; Adolescents are fasted from food, but allowed ad libitum water for at least $10 \mathrm{~h}$ prior to their visit. They are asked to limit their physical activity for this same time frame. To limit the influence of acute inflammation on our biomarkers, adolescents are immediately rescheduled if they report: 1) any illness in the past week or surgery in the past month; 2) immunizations within the past 2 weeks; or, 3) use of antibiotics, corticosteroids or other prescription anti-inflammatories within the past 10 days. Adolescents are semi-reclined (head and feet with similar elevation) in a blood draw chair. Whenever possible, blood is collected from an antecubital site, but when necessary, radial or hand venipuncture procedures are used. In all cases, blood is collected using pediatric gauge butterfly needles and a vacutainer system and universal precautions and OSHA guidelines are followed for blood handling. When necessary, pain reduction techniques such as use of the Buzzy $^{\circ}$ are employed to minimize patient anxiety. A total of $10 \mathrm{ml}$ of blood is collected in serum separator tubes identified with only a subject ID and date. Blood is allowed to coagulate at room temperature for $20 \mathrm{~min}$ and spun at $4{ }^{\circ} \mathrm{C}$ for $15 \mathrm{~min}$ at $3000 \mathrm{rpm}$. To limit freeze/thaw cycling, serum is divided into multiple aliquots of $500-1000 \mu \mathrm{l}$ and stored at $-80{ }^{\circ} \mathrm{C}$ until analysis.

Inflammatory biomarkers and hormone levels in serum are analyzed by the Cytokine Analysis Facility at the University of North Carolina at Chapel Hill using the Multi-Plex (Bio-Rad, Hercules, CA) and the SpectraMax M2 ELISA plate reader. Samples are analyzed in duplicate with appropriate quality controls and all samples from a single individual are run in the same ELISA plate to minimize inter-assay variability and to insure comparability of assays across ages. Lipid profiles and glucose are assayed in the UNC Greensboro Exercise Physiology Laboratory using commercially available ELISA systems and the EPOCH plate reader (BioTek, Winooski, VT). Specifically, lipid profiles (total cholesterol, triglycerides, low-density lipoproteins and highdensity lipoproteins) are assayed using colorimetric reagents (Wako USA, Richmond, VA) and glucose is assayed using a colorimetric assay (Caymen Chemical, Ann Arbor, MI). As outlined above for the inflammatory biomarkers, all samples from a given individual are assayed in the same ELISA plate.

Obesity Indices; At all data collection points, height is measured to the nearest $0.1 \mathrm{~cm}$ with a wall mounted, calibrated stadiometer (SECA, Chino CA) and weight is measured to the nearest $0.1 \mathrm{~kg}$ with a balance-beam scale (Detecto-medic, Brooklyn NY). Body mass index (BMI) is calculated using the standard formula [weight $(\mathrm{kg}) /$ height $\left(\mathrm{m}^{2}\right)$ ] and BMI percentiles were assigned by sex and age (in months) according to the most recent Center for Disease Control growth charts [68]. Healthy weight was defined as BMI $>5$ th percentile and $<85$ th percentile for age and sex, overweight defined as values between the 85th and 95th percentile, and obesity defined by a BMI at the 95th percentile or greater [69]. Waist circumference (WC) and hip circumference $(\mathrm{HC})$ are measured to the nearest $0.1 \mathrm{~cm}$ using a Gulick tension-tape measure by a sex-matched research assistant in a private location in the laboratory. WC is taken at the smallest part of the abdominal area ("natural waist") and $\mathrm{HC}$ is taken at the maximal extension of the buttocks as outlined in the anthropometric standardization manual [70]. Both lying and standing sagittal abdominal diameter (SAD) are taken at the L4-L5 vertebral level to the nearest $0.1 \mathrm{~cm}$ using a Holtain-Kahn abdominal caliper (Croswell, UK).

At the YA visit only, the BODPOD (Cosmed, Concord, CA, USA), is used to assess body composition. The BODPOD is an air displacement plethysmography 
device that has been shown to be a valid and reliable tool for the measurement of body density across a range of individuals, including those who are overweight or obese, and is considerably less burdensome on participants than hydrostatic weighing $[71,72]$. Standard manufacturer calibration procedures for volume are used with the scale calibrated daily using a $20 \mathrm{~kg}$ calibration weight. Participants enter the chamber wearing minimal clothing (spandex shorts, bra), and a swimming cap covering their hair where possible. Standard measurement procedures are followed. The subject's thoracic lung volume is measured using the BODPOD breathing circuit system with calculations for body composition then performed using age and race appropriate algorithms built into the BODPOD system. The primary outcome variables are lean body mass, fat mass and percent body fat.

Blood Pressure; Upon arrival at the laboratory and after obtaining consent/assent, participants rest quietly for $5 \mathrm{~min}$ with arm supported at heart level and feet on the floor, as outlined by the Seventh Report of the Joint National Committee on Prevention, Detection, Evaluation and Treatment of High Blood Pressure [73]. Manual cuff blood pressure measurements are repeated two times with at least 5 min between measures. Resting heart rate is also taken twice at this time.

Peak Exercise Test (Fitness); A graded exercise test is performed in our study sample as a measure of cardiovascular fitness and to assess the heart rate and autonomic response to exercise at the YA visit only. Given the additional components of the exercise testing paradigm that are part of the visit (i.e. the HRV assessment), the duration of the exercise test has to be similar across participants. Yet, the duration of many traditional graded exercise tests is highly dependent on individual fitness level, making many of these inappropriate choices for the current study. The goal of the pilot testing was to find a protocol that would result in an individual attaining volitional fatigue in 10-12 min following the onset of exercise. Pilot testing determined that a Modified Treadmill Protocol should be used for our adolescent population.

The actual exercise testing protocol consists of an initial 3 min period with the goal of developing comfort with the treadmill and achieving a self-determined speed (walking or jogging) that one would anticipate being able to maintain for at least $10-15 \mathrm{~min}$. At the end of the 3min period, the treadmill speed remains constant for the remainder of the test, with the incline increasing by $3 \%$ every 2 min after that point $(0 \% @ 3 \mathrm{~min}, 3 \% @ 6 \mathrm{~min}$, $6 \% @ 9 \mathrm{~min}$, and onwards) until volitional fatigue, or test termination by the research staff. Certified ACSM Clinical Exercise Physiologists are responsible for conducting the exercise testing. Participant health information is adjudicated by study staff with reference to the ACSM Guidelines for Exercise Testing and Prescription
[74]. Because there is no medical supervision, some individuals may only be cleared for sub-maximal exercise testing in this environment. These participants will undergo the same testing procedures; however, the test is terminated when $85 \%$ of the age-predicted maximal heart rate is reached.

Expired air is collected through a Hans Rudolph mouthpiece and gas analysis is performed using the Parvo Medics TrueOne 2400 (Parvo, USA). Standard gas and flow calibration procedures are completed prior to every test following manufacturer instructions. Five minutes of seated resting breathing prior to the test allows the participant to get accustomed to breathing with the mouthpiece. During the exercise test, heart rate is monitored real-time using the Polar V800 (Polar, Finland), and the Rating of Perceived Exertion (RPE), obtained at the end of each stage [75]. Peak oxygen consumption, defined as the highest value attained during testing, is the primary outcome for the exercise test. This measure is a robust indicator of overall health status and is a promising, yet rarely used marker of CVD risk in this population. Heart rate recovery dynamics are assessed by monitoring heart rate in a seated position for $10 \mathrm{~min}$ following the cessation of exercise. Participants who complete a sub-maximal versus peak exercise test will be treated separately in analyses that utilize the exercise data.

Heart Rate Variability; An orthostatic challenge is used to assess autonomic function, via changes in heart rate variability (HRV), to a mild physiologic stressor (postural change) while a peak exercise session is used to assess changes in autonomic function in response to a major physiologic stressor. These physical stressors are used as a means of comparing autonomic function to the psychological stressor paradigms that participants underwent during their early developmental years as part of RIGHT Track. While the measures of HRV collected during this session are not directly comparable to the measures of HRV collected during the early years of the RIGHT Track study, they will provide complementary information regarding the role of the autonomic nervous system as a regulator of cardiac control. Variability in heart rate ( $R-R$ intervals), is collected un-paced at rest using a wireless BioNomadix ECG with respiration strap connected to the BIOPAC MP150 (Biopac Systems, Goleta, CA, USA). Participants spend $5 \mathrm{~min}$ supine, 5 min seated and 5 min standing in a small, lit room with potential visual and auditory distractions minimized. While high frequency HRV may be recorded over periods as short as 60s [76], low frequency HRV requires long periods of data collection for reliable spectral information. In addition, $5 \mathrm{~min}$ of data collection in each postural position provides adequate data points to assess regularity metrics, such as approximate entropy. The Acknowledge software program (Biopac Systems, Goleta, 
CA, USA) collects the data real-time, and exported data is processed and analyzed for time, frequency and nonlinear domains using Kubios software (University of Eastern Finland). Artifacts are removed using manual checks, and artifact correction and de-trending is completed with the Kubios software. The orthostatic challenge is completed both pre-exercise and approximately 20 min post exercise. During the exercise portion of the visit, heart rate and HRV are also assessed using a Polar RS800CX (Polar, Finland). Data files are downloaded using the Polar ProTrainer 5 software (Polar, Finland) and exported to Kubios for further cleaning, processing and analysis.

\section{Health behaviors}

Dietary Recall \& Analyses; At T1 and YA, dietary recalls are assessed by the Nutrition Obesity Research Center (NORC) at the University of North Carolina Chapel Hill. Dietary intake data is collected and analyzed using the Nutrition Data System for Research (NDSR) software developed by the Nutrition Coordination Center (NCC), University of Minnesota, Minneapolis, MN. Three 24-h dietary recalls are collected by telephone ( 2 weekdays and one weekend day). To increase the accuracy of recall, a trained interviewer conducts the sessions using a multiple-pass procedure for recalling food intake [77]. First, a list of all foods and beverages consumed in the past $24 \mathrm{~h}$ is obtained from the participant. Next, this list is reviewed with the participant for completeness and accuracy. Then the amount consumed and the method of preparation of each item is collected. Finally, the detailed information is reviewed again with the participant for completeness and correctness. The recall is then reviewed by the NORC coordinator using the quality assurance guidelines of NDSR. This method has been validated against doubly-labeled water as an accurate measure of energy intake [78]. To reflect the marketplace throughout the study, dietary intake data is analyzed using multiple versions of the Nutrition Data System for Research software. Installation of software upgrades are based on the currently available version and timed so that data collection is not disrupted. Final calculation is completed using the most current NDSR version. The NDSR time-related database updates only analytic information and maintains nutrient profiles in the original version used for data collection.

Data from the 3 days of recall is averaged to determine the quality of the diet, using the Health Eating Index (HEI) 2010 score [79]. The HEI is based on the dietary recommendations of the 2010 Dietary Guidelines for Americans. It consists of 12 components: total fruit, whole fruit, total vegetables, greens and beans, whole grains, dairy total protein foods, seafood and plant proteins, fatty acids, refined grains, sodium, and empty calories to assess the quality of the diet. A score is assigned to each component and then summed (range of total score: 0 to 100). The HEI scores are calculated from the nutrient and food group outputs as described by Wiltheiss et al. [80]. Data from the NDSR is also used to assess energy and other nutrient intake.

Health Behavior Questionnaires; At all adolescent data collection time points (T1, T2 and YA), individuals complete several self-report measures of health behaviors (see Table 4 for details). In addition, at T2 only, participants complete a sports history questionnaire to collect information on sport engagement at younger ages and the primary reasons for continued engagement versus attrition from sport activity. The sports history questionnaire is currently being validated in our RIGHT Track Health sample. At T1 and T2 only, parents also complete modified items from the Behavioral Risk Factor Surveillance System (BRFSS) about their own diet and exercise behaviors.

Accelerometry; Following the completion of the YA visit, participants are given an Actigraph GT9X Link accelerometer (Actigraph LLC, FL, USA) and instructed to wear it on their non-dominant wrist $24 \mathrm{~h}$ per day for the next 7 days. Participants are advised to remove the device for water-based activities, and where regulated by sporting competition or occupation. In addition to builtin wear time validation functions, participants also record non-wear time on a log sheet. After 7 days of wear, participants mail the device and log sheet back to the study team and compliance is assessed. Individuals who do not meet the minimal wear time criteria (wore the device less than 4 days), will be resent an accelerometer for a further wear period. More than 4 days of wear time is recommended for the assessment of usual physical activity, however it is currently unknown what the minimum wear period is when utilizing a $24 \mathrm{~h}$ protocol, so we decided to use conservative measures. It is suggested that 6 days are required for accurate assessment of sedentary time [81] and 4-7 days are required for accurate assessment of sleep patterns in children [82], but no wear time validation for sleep patterns is currently available for adolescents. Accelerometers are set up to collect at $30 \mathrm{~Hz}$ for the 7 day period and downloaded into the Actilife software (Actigraph LL, FL, USA). The wrist worn protocol was selected to reflect current data collection procedures used by NHANES, and to allow the collection of objective measurement of sleep, which is a health behavior that is receiving increasing attention for its important role in physical and mental health in youth. Preliminary data from the NHANES switch to wrist worn accelerometry has identified significantly improved compliance over traditional waist worn procedures [83]. Additionally, the number of hours of wear time has been shown to influence estimates of physical 
Table 4 Key self-reported measures of adolescent health behaviors collected at adolescent time points (Time 1, Time 2 and Young Adult)

\begin{tabular}{|c|c|c|}
\hline Measure & Subscales & Resources \\
\hline \multicolumn{3}{|l|}{ Diet and Eating Regulation } \\
\hline \multirow[t]{3}{*}{ Three-Factor Eating Questionnaire } & Restraint & \multirow[t]{3}{*}{ Stunkard \& Messick (1985) } \\
\hline & Disinhibition & \\
\hline & Hunger & \\
\hline Adolescent Food Habits Questionnaire & $\begin{array}{l}\text { Adolescent healthy eating behavior } \\
\text { (global summary scale indicative of } \\
\text { consumption of specific foods, food } \\
\text { purchases and preparations; items } \\
\text { refer to both healthy \& unhealthy } \\
\text { behaviors.) }\end{array}$ & Johnson, Wardle, \& Griffith (2002) \\
\hline \multicolumn{3}{|l|}{ Physical Activity and Sedentary Behaviors } \\
\hline \multirow[t]{5}{*}{ Godin Leisure-Time Exercise Questionnaire } & Light & \multirow[t]{5}{*}{ Godin \& Shephard (1985); Jacobs et al. (1993) } \\
\hline & Moderate & \\
\hline & Strenuous & \\
\hline & Total & \\
\hline & "Sweat-Breaking" Physical Activity & \\
\hline \multirow[t]{4}{*}{ Sedentary Behavior } & Total inactive hours & \multirow{4}{*}{$\begin{array}{l}\text { Gortmaker et al. 1999; Utter et al 2003; Harvard } \\
\text { School of Public Health Nutrition Dept WebPage; } \\
\text { http://regepi.bwh.harvard.edu/health }\end{array}$} \\
\hline & Hours of TV/DVD/video viewing & \\
\hline & Hours of computer use & \\
\hline & Hours of sedentary electronic games & \\
\hline \multicolumn{3}{|l|}{ Sleep } \\
\hline \multirow[t]{8}{*}{ Pittsburgh Sleep Quality Index } & Sleep Quality & \multirow[t]{8}{*}{ Buysse, Reynolds, Monk, Berman, \& Kupfer (1988) } \\
\hline & Sleep Latency & \\
\hline & Sleep Duration & \\
\hline & Habitual Sleep Efficiency & \\
\hline & Sleep Disturbance & \\
\hline & Use of Sleep Medication & \\
\hline & Daytime Dysfunction & \\
\hline & Global Score & \\
\hline \multicolumn{3}{|l|}{ Instruments Assessing Multiple Health Behaviors } \\
\hline \multirow[t]{4}{*}{ Youth Risk Behavior Survey } & Tobacco Use & \multirow{4}{*}{$\begin{array}{l}\text { Brener, Collins, Kann, Warren, \& Williams (1995); } \\
\text { Centers for Disease Control and Prevention (2012) }\end{array}$} \\
\hline & Alcohol \& Other drug use & \\
\hline & Dietary Behaviors & \\
\hline & Physical Activity & \\
\hline
\end{tabular}

activity, so a $24 \mathrm{~h}$ protocol may assist in ensuring the accuracy of measurement [84]. With several years of data collection required for the present study, and the advancing nature of techniques in the processing and analyses of accelerometry derived information, it is currently unknown which algorithms and methods will be used as our final outcomes. All accelerometry files will be batch processed at the end of the data collection utilizing currently accepted and validated standards. It is expected that time spent in sedentary (sedentary time), in low intensity physical activity (LPA) and in moderate-to- vigorous physical activity (MVPA) will be computed using established thresholds (sedentary time: $<100 \mathrm{cpm}$, LPA: 100-2295 cpm, MVPA: $\geq 2296 \mathrm{cpm}$ ) [85, 86].

Control Variables and Potential Confounds: At each age, participants bring their prescribed medications to the laboratory; interviewers record dosage, frequency of use, and reason for use. Glucocorticoids, anti-inflammatory and immunosuppressant drugs are of special interest with respect to inflammation, although aggregate measures of any medication use tend to be robustly associated with inflammatory markers in adolescents [27]. We also 
administer a "Laboratory Day Checklist" which measures sleep, exercise, and substance use in the $24 \mathrm{~h}$ before the laboratory visit. Females are also asked to report the first day of their last menstrual period, information about their typical menstrual cycles, and use of hormonal contraceptives. We also assess family history of health, with a special focus on autoimmune, inflammatory, and cardiovascular health conditions. The laboratory day checklist is administered before the blood draw and closely assesses any medical conditions that would preclude us from conducting the draws (e.g., blood disorders). In addition to these control variables, a number of constructs that could be associated with self-regulation, health behaviors, and cardiovascular risk markers are assessed, including somatic symptoms with the Children's Somatization Inventory (CSI-24) and depressive symptoms with the Short Mood and Feelings Questionnaire. In addition, the original ongoing longitudinal RIGHT Track study assessed a wealth of self-regulation and psychological variables during adolescence (i.e., ages 15.5 and 17.5) that can be included as control variables in our analyses.

\section{Discussion}

The main aim of the RIGHT Track Health Study is to examine the role of childhood physiological, behavioral, and emotional self-regulation in the development of adolescent cardiovascular risk factors and to test the role of health behaviors in these associations. This current study leverages an ongoing $15^{+}$-year study with a prospective-longitudinal community study extending from childhood onwards and uses high-quality, repeated multi-method, biobehavioral measures of emotional, behavioral, and physiological SR and high-quality, repeated multi-method measures of psychosocial adversity. During adolescence, the RIGHT Track Health Study adds valid, longitudinal assessments of CVR and health behaviors. The current paper provides basic methods for collecting original/historic measures on this sample (starting at the age of 2 years) and detailed information on the cardiovascular risk and health behavior data assessed during adolescence and into young adulthood.

The fine-grained study of childhood self-regulation, health behaviors and adolescent cardiovascular risk has been limited by both a dearth of longitudinal data and a lack of extensive measures of these constructs. One of the strengths of the RIGHT Track Health Study is the inclusion of multiple data collection time points during childhood and an assessment of self-regulation in terms of physiological, emotional, and behavioral domains, which allows this study to test whether poor selfregulation between ages 2 to 10 manifests itself in increases in cardiovascular risk in late adolescence. Further, we can test whether specific domains of selfregulation (behavioral, emotional or physiological) play a unique role in cardiovascular risk or whether the accumulation of self-regulatory deficits across domains is more significant.

In addition, we will have multiple biomarker data collections within late adolescence and young adulthood, developmental periods when most individuals are navigating major life changes (e.g., changes in social and family relations and schooling) and gaining increasing autonomy from their primary caregivers. During this time, health behaviors likely increasingly reflect a young person's own choices and become increasingly stable with age. Indeed, the childhood self-regulation $\rightarrow$ adolescent health behavior links that we examine here may be critical in long term cardiovascular and other health outcomes. Our data will allow us to test whether health behaviors in adolescence, including exercise, nutrition, sleep and substance use mediate linkages from selfregulation in childhood to cardiovascular risk in adolescence and to investigate the directionality of the link between health behaviors and cardiovascular risk during this developmental period.

An additional major strength of the current study is the longitudinal assessment of childhood adversity (i.e. poverty, harsh parenting). Psychosocial adversity is associated with both poor self-regulation and later cardiovascular risk [87-90]. Our study will test whether children with regulatory difficulties who are also exposed to childhood adversity have higher levels of cardiovascular risk. We will also explore patterns of this relationship for males and females and for European and African American individuals.

One limitation of the RIGHT Track Health Study is that our sample is limited to the individuals who were originally enrolled in the longitudinal study when they were 2 (approximately 1.5 decades ago). Over the years, attrition in the cohort due to geographic relocation of families and loss of contact with some participants limits our ability to follow every participant. In addition, as in most longitudinal studies, some individuals were only able to participate intermittently, missing some assessments, but resuming their participation in the study at later time points. Thus, we recognize that some bias may exist in our sample since participants who remained involved may have lower geographic mobility and/or intrinsic interests that motivate them to continue participating in health-related research. However, the RIGHT Track Study has found limited support for selective attrition and attrition rates for the study are similar to other high-quality longitudinal studies. Participants who continued versus those who ceased involvement did not significantly differ on many key characteristics, including socioeconomic status, race, and gender. Whether this pattern in attrition will hold in adolescence remains to be seen with our new data collection. 
The RIGHT Track Health Study data will provide valuable information for youth health care and may inform policy makers about the specific health behaviors (e.g. diet, physical activity, sleep, substance use) that are most influenced by early childhood regulatory abilities. In addition, assessing the trajectories of these cardiovascular risk factors from childhood to adolescence may indicate critical 'windows' for reducing certain risk factors.

In summary, individuals in the RIGHT Track Health Study are prospectively followed from age 2 through young adulthood in an effort to understand how selfregulatory behavior throughout childhood alters the trajectories of various cardiovascular risk factors during late adolescence via health behaviors. Insights provided by these data could contribute to our understanding of chronic disease prevention early in life when intervention efforts are most cost-effective and behavior may be more malleable [91].

\section{Additional file}

Additional file 1: RT Empirical Publications List. (DOCX $22 \mathrm{~kb}$ )

\begin{abstract}
Abbreviations
BMI, body mass index; CVD, cardiovascular disease; HC, hip circumference; $\mathrm{HEl}$, healthy eating index; HP, heart period; HRV, heart rate variability; LPA, Iow intensity physical activity; MVPA, moderate-to-vigorous physical activity; NDSR, nutrition diet system for research; NORC, Nutrition Obesity Research Center; RPE, rating of perceived exertion; RSA, respiratory sinus arrhythmia; SAD, sagittal abdominal diameter; SES, socioeconomic status; SR, self regulation; $\mathrm{T} 1$, time $1 ; \mathrm{T} 2$, time $2 ; \mathrm{WC}$, waist circumference; $Y A$, young adult
\end{abstract}

\section{Acknowledgements}

We would like to thank the RIGHT Track families for their continued involvement in the study and for their time and effort. We would also like to thank the many research staff and graduate students that have contributed to the success of this longitudinal study.

\section{Funding}

This study is currently funded by the Eunice Kennedy Shriver National Institute of Child Health \& Human Development of the National Institutes of Health under award number R01HD078346 [PI; Shanahan] and by NIH award number DK56350 to the Nutrition Obesity Research Center (NORC) at the University of North Carolina Chapel Hill. The historic data collection was funded by NIMH 55625, NIMH 55584 \& NIMH 58144 [Pl; Calkins]. The content is solely the responsibility of the authors and does not necessarily represent the official views of the National Institutes of Health.

\section{Authors' contributions}

Laurie Wideman (LW), was responsible for study design, grant writing and was the primary author of the current manuscript; Susan D Calkins (SDC), was responsible for the historic study design, grant writing for the historic studies and the current study and final review and approval of the current manuscript; James A Janssen (JAJ), contributed to the current study design and preparation of the current manuscript; Cheryl A Lovelady (CAL), contributed to the current study design, grant writing for the current study and final review and approval of the current manuscript; Jessica M Dollar (JMD), was responsible for historic data collection, current study design and preparation of the current manuscript; Susan P Keane (SPK), contributed to the historic study design and grant writing, grant writing for the current study and final review and approval of the current manuscript; Eliana M Perrin (EMP), contributed to the current study design and grant writing and final review and approval of the current manuscript \& Lilly Shanahan (LS), contributed to the current study design, was the primary author of the grant and contributed to preparation of the current manuscript. All authors read and approved the final manuscript.

\section{Competing interests}

The authors have no competing interests to report.

\section{Ethics approval \& consent}

All individuals are consented at every visit. All procedures described in this manuscript have been approved by the University of North Carolina Greensboro Institutional Review Board (\#11-0360; PI Wideman and \#09-0427; PI Calkins) and the University of North Carolina Chapel Hill Institutional Review Board (\#12-1817; PI Shanahan).

\section{Author details}

${ }^{1}$ Department of Kinesiology, University of North Carolina Greensboro, Greensboro 27402, NC, USA. ²Department of Human Development and Family Studies, University of North Carolina Greensboro, Greensboro 27402, NC, USA. ${ }^{3}$ Department of Nutrition, University of North Carolina Greensboro,

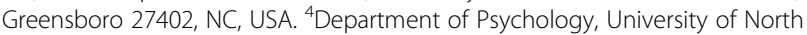
Carolina Greensboro, Greensboro 27402, NC, USA. ${ }^{5}$ Division of General Pediatrics and Adolescent Medicine, Department of Pediatrics, University of North Carolina Chapel Hill, Chapel Hill 27599-7225, NC, USA. ${ }^{6}$ Department of Psychology and Neuroscience, University of North Carolina Chapel Hill, Chapel Hill 27599-3270, NC, USA.

Received: 24 April 2016 Accepted: 18 May 2016

Published online: 01 June 2016

\section{References}

1. Skinner AC, Skelton JA. Prevalence and trends in obesity and severe obesity among children in the United States, 1999-2012. JAMA Pediatr. 2014;168(6): $561-6$.

2. Ogden C, Carroll M, Kit B, Flegal K. Prevalence of childhood and adult obesity in the United States, 2011-2012. JAMA. 2014;311(8):806-14.

3. Freedman DS. Clustering of coronary heart disease risk factors among obese children. J Pediatr Endocrinol Metab. 2002;15(8):1099-108.

4. Gidding SS, Bao W, Srinivasan SR, Berenson GS. Effects of secular trends in obesity on coronary risk factors in children: The Bogalusa Heart Study. J Pediatr. 1995;127(6):868-74

5. Kirk S, Zeller M, Claytor R, Santangelo M, Khoury PR, Daniels SR. The relationship of health outcomes to improvement in $\mathrm{BMI}$ in children and adolescents. Obes Res. 2005;13(5):876-82.

6. Savoye $M$, Shaw M, Dziura J, Tamborlane WV, Rose P, Guandalini C, Goldberg-Gell R, Burgert TS, Cali AM, Weiss R, et al. Effects of a weight management program on body composition and metabolic parameters in overweight children: A randomized controlled trial. JAMA. 2007;297(24): 2697-704.

7. Skinner AC, Mayer ML, Flower K, Perrin EM, Weinberger M. Using BMI to determine cardiovascular risk in childhood: How do the BMl cutoffs fare. Pediatrics. 2009;124(5):e905-912.

8. Bekkers MB, Brunekreef B, Koppelman GH, Kerkhof M, de Jongste JC, Smit $\mathrm{HA}$, Wijga AH. BMI and waist circumference: Cross-sectional and prospective associations with blood pressure and cholesterol in 12-year-olds. PLOS One. 2012;7(12):e51801.

9. Skinner AC, Perrin EM, Moss LA, Skelton JA. Cardiometabolic risks and severity of obesity in children and young adults. N Engl J Med. 2015;373(14): 1307-17.

10. Duncan GE, Li SM, Zhou XH. Prevalence and trends of a metabolic syndrome phenotype among U.S. adolescents, 1999-2000. Diabetes Care. 2004;27(10):2438-43.

11. Ford ES. Risks for all-cause mortality, cardiovascular disease, and diabetes associated with the metabolic syndrome: A summary of the evidence. Diabetes Care. 2005:28(7):1769-78.

12. Ford ES, Capewell S. Coronary heart disease mortality among young adults in the U.S. from 1980 through 2002: Concealed leveling of mortality rates. J Am Coll Cardiol. 2007;50(22):2128-32.

13. Lloyd-Jones D, Adams R, Carnethon M, De Simone G, Ferguson TB, Flegal K, Ford E, Furie K, Go A, Greenlund K, et al. Heart disease and stroke statistics 2009 update: A report from the American Heart Association Statistics Committee and Stroke Statistics Subcommittee. Circulation. 2009;119(3):480-6. 
14. Weiss R, Dziura J, Burgert TS, Tamborlane W, Taksali SE, Yeckel CW, Allen K, Lopes M, Savoye M, Morrison J, et al. Obesity and the metabolic syndrome in children and adolescents. N Engl J Med. 2004;250(23):2362-74.

15. Cook S, Auinger P, Li C, Ford ES. Metabolic syndrome rates in United States adolescents, from the National Health and Nutrition Examination Survey, 1999-2002. J Pediatr. 2008;152(2):165-70.

16. Cook S, Weitzman M, Auinger P, Nguyen M, Dietz WH. Prevalence of a metabolic syndrome phenotype in adolescents: Findings from the third National Health and Nutrition Examination Survey, 1988-1994. Arch Pediatr Adolesc Med. 2003;157(8):821-7.

17. de Ferranti SD, Gauvreau K, Ludwig DS, Neufeld EJ, Newburger JW, Rifai N. Prevalence of the metabolic syndrome in American adolescents: Findings from the Third National Health and Nutrition Examination Survey. Circulation. 2004;110(16):2494-7.

18. Miller JM, Kaylor MB, Johannsson M, Bay C, Churilla JR. Prevalence of metabolic syndrome and individual criterion in US adolescents: 2001-2010 National Health and Nutrition Examination Survey. Metab Syndr Relat Disord. 2014;12(10):527-32.

19. Skinner AC, Steiner MJ, Henderson FW, Perrin EM. Multiple markers of inflammation and weight status: Cross-sectional analyses throughout childhood. Pediatrics. 2010;125(4):801-19.

20. Going SB, Lohman TG, Cussler EC, Williams DP, Morrison JA, Horn PS. Percent body fat and chronic disease risk factors in U.S. children and youth. Am J Prev Med. 2011;41(4 Suppl 2):S77-86.

21. Shanahan L, Freeman J, Bauldry S. Is very high C-reactive protein in young adults associated with indicators of chronic disease risk? Psychoneuroendocrinology. 2014;40:76-85.

22. Ridker PM. C-reactive protein and the prediction of cardiovascular events among those at intermediate risk: Moving an inflammatory hypothesis toward consensus. J Am Coll Cardiol. 2007:29(21):2129-38.

23. Ridker PM, Buring JE, Cook NR, Rifai N. C-reactive protein, the metabolic syndrome, and risk of incident cardiovascular events: An 8-year follow-up of 14719 initially healthy American women. Circulation. 2003;107(3):391-7.

24. Ridker PM, Buring JE, Shih J, Matias M, Hennekens $\mathrm{CH}$. Prospective study of C-reactive protein and the risk of future cardiovascular events among apparently healthy women. Circulation. 1998:98(8):731-3.

25. Ishii S, Karlamangla AS, Bote M, Irwin MR, Jacobs DRJ, Cho HJ, Seeman TE. Gender, obesity and repeated elevation of $\mathrm{C}$-reactive protein: Data from the CARDIA cohort. PLoS One. 2012;7(4):e36062.

26. Miller GE, Freedland KE, Carney RM, Stetler CA, Banks WA. Pathways linking depression, adiposity, and inflammatory markers in healthy young adults. Brain Behav Immun. 2003;17(4):276-85.

27. Shanahan L, Copeland WE, Worthman C, Erkanli A, Angold A, Costello EJ. Sex-differentiated changes in C-reactive protein from ages 9 to 21: The contributions of BMl and physical/sexual maturation. Psychoneuroendocrinology. 2013;38(10):2209-17.

28. Kapiotis S, Holzer G, Schaller G, Haumer M, Widhalm H, Weghuber D, Jilma B, Röggla $G$, Wolzt M, Widhalm $K$, et al. A proinflammatory state is detectable in obese children and is accompanied by functional and morphological vascular changes. Arterioscler Thromb Vasc Biol. 2006;26(11):2541-6.

29. Lim SM, Kim HC, Lee HS, Lee JY, Suh M, Ahn SV. Association between blood pressure and carotid intima-media thickness. J Pediatr. 2009;154(5):667-71.

30. Reinehr T, Kiess W, de Sousa G, Stoffel-Wagner B, Wunsch R. Intima media thickness in childhood obesity: Relations to inflammatory marker, glucose metabolism, and blood pressure. Metabolism. 2006;55(1):113-8.

31. Cook DG, Mendall MA, Whincup P, Isasi CR. C-reactive protein concentration in children: Relationship to adiposity and other cardiovascular risk factors. Atherosclerosis. 2000;149(1):139-50

32. Wunsch R, de Sousa G, Toschke AM, Reinehr T. Intima-media thickness in obese children before and after weight loss. Pediatrics. 2006;118(6):2334-40.

33. Hartiala O, Magnussen CG, Kajander S, Knuuti J, Ukkonen H, Saraste A, Rinta-Kiikka I, Kainulainen S, Kähönen M, Hutri-Kähönen N, et al. Adolescence risk factors are predictive of coronary artery calcification at middle age: The cardiovascular risk in young Finns study. J Am Coll Cardiol. 2012;60(15):1364-70.

34. Janssen I, Katzmarzyk PT, Srinivasan SR, Chen W, Malina RM, Bouchard C, Berenson GS. Utility of childhood BMI in the prediction of adulthood disease: Comparison of national and international references. Obes Res. 2005:13(6):1106-15.

35. Juonala M, G MC, Berenson GS, Venn A, Burns TL, Sabin MA, Srinivasan SR, Daniels SR, Davis PH, Chen W, et al. Childhood adiposity, adult adiposity, and cardiovascular risk factors. N Engl J Med. 2011;365(20):1876-85.
36. Llewellyn A, Simmonds M, Owen CG, Woolacott N. Childhood obesity as a predictor of morbidity in adulthood: a systematic review and meta-analysis. Obes Rev. 2015;17(1):56-67.

37. Reilly JJ, Kelly J. Long-term impact of overweight and obesity in childhood and adolescence on morbidity and premature mortality in adulthood: systematic review. Int J Obes (Lond). 2011;35(7):891-8.

38. Reilly JJ, Methven E, McDowell ZC, Hacking B, Alexander D, Stewart L, Kelnar CJ. Health consequences of obesity. Arch Dis Child. 2003;88(9):748-52.

39. Hatzenbuehler ML, McLaughlin KA, Slopen N. Sexual orientation disparities in cardiovascular biomarkers among young adults. Am J Prev Med. 2013; 44(6):612-21.

40. Nguyen QC, Tabor JW, Entzel PP, Lau Y, Suchindran C, Hussey JM, Halpern $C T$, Harris KM, Whitsel EA. Discordance in national estimates of hypertension among young adults. Epidemiology. 2011;22(4):532-41.

41. Rosner B, Cook NR, Daniels S, Falkner B: Childhood blood pressure trends and risk factors for high blood pressure: The NHANES experience 1988-2008. Hypertension 2013, [Epub ahead of print]

42. Bauldry S, Shanahan MJ, Boardman JD, Miech RA, Macmillan R. A life course model of self-rated health through adolescence and young adulthood. Soc Sci Med. 2012;75(7):1311-20

43. Cui W, Zack M. Trends in health-related quality of life among adolescents in the United States, 2001-2010. Prev Chronic Dis. 2013;10:E111.

44. Perrin EM, Finkle JP, Benjamin JT. Obesity prevention and the primary care pediatrician's office. Curr Opin Pediatr. 2007;19(3):354-61.

45. Schwartz RP, Vitolins MZ, Case LD, Armstrong SC, Perrin EM, Cialone J, Bell RA. The YMCA Healthy, Fit, and Strong Program: A community-based, family-centered, low-cost obesity prevention/treatment pilot study. Childhood Obes. 2012:8(6):577-82.

46. Burdette HL, Whitaker RC. A national study of neighborhood safety, outdoor play, television viewing, and obesity in preschool children. Pediatrics. 2005; 116(3):657-62.

47. Ciampa PJ, Kumar D, Barkin SL, Sanders LM, Yin HS, Perrin EM, Rothman RL Interventions aimed at decreasing obesity in children younger than 2 years: A systematic review. Arch Pediatr Adolesc Med. 2010;164(12):1098-104.

48. Ogden CL, Carroll MD, Curtin LR, Lamb MM, Flegal KM. Prevalence of high body mass index in US children and adolescents, 2007-2008. JAMA. 2010; 303(3):242-9.

49. Ogden CL, Carroll MD, Flegal KM. High body mass index for age among US children and adolescents, 2003-2006. JAMA. 2008;299(20):2401-5.

50. Ogden CL, Carroll MD, Kit BK, Flegal KM. Prevalence of obesity and trends in body mass index among US children and adolescents, 1999-2010. JAMA 2012;307(5):483-90.

51. CDC. Obesity prevalence among low-income, preschool-aged children New York City and Los Angeles County, 2003-2011. Morb Mortal Wkly Rep. 2013:62(2):17-37.

52. Moffitt TE, Arseneault L, Belsky D, Dickson N, Hancox RJ, Harrington $H$ Houts R, Poulton R, Roberts BW, Ross S, et al. A gradient of childhood selfcontrol predicts health, wealth, and public safety. Proc Natl Acad Sci. 2011; 108(7):2693-8

53. Calkins S. Conceptual and methodological challenges to the study of emotion regulation and psychopathology. J Psychopathol Behav Assess. 2010;32:92-5.

54. Baumeister R, Vohs K, editors. Handbook of self-regulation: research, theory and applications. New York: Guilford; 2004.

55. Calkins SD, Fox NA. Self-regulatory processes in early personality development: a multilevel approach to the study of childhood social withdrawal and aggression. Dev Psychopathol. 2002;14(3):477-98.

56. Achenbach T. Manual for the child behavior checklist/2-3 and 1992 profile. Burlington: University of Vermont Department of Psychiatry; 1992

57. Calkins SD, Dedmon SE, Gill KL, Lomax LE, Johnson LM. Frustration in infancy: implications for emotion regulation, physiological processes, and temperament. Infancy. 2002;3(2):175-97.

58. Porges SW. The Polyvagal Theory: phylogenetic contributions to social behavior. Physiol Behav. 2003;79(3):503-13.

59. Porges SW. The polyvagal perspective. Biol Psychol. 2007:74(2):116-43.

60. Perry NB, Calkins SD, Bell MA. Indirect effects of maternal sensitivity on infant emotion regulation behaviors: The role of vagal withdrawal. Infancy. 2015;21(2):128-53.

61. Goldsmith $\mathrm{HH}$, Rothbart MK. The laboratory temperament assessment battery (LAB-TAB). Madison: University of Wisconsin; 1993.

62. Porges SW. Method and apparatus for evaluating rhythmic oscillations in aperiodic physiological response systems. 1985. 
63. Calkins SD, Keane SP. Cardiac vagal regulation across the preschool period: Stability, continuity, and implications for childhood adjustment. Dev Psychobiol. 2004;45(3):101-12.

64. Blair C, Peters R. Physiological and neurocognitive correlates of adaptive behavior in preschool among children in Head Start. Dev Neuropsychol. 2003;24(1):479-97.

65. Porges SW, Doussard-Roosevelt JA, Portales AL, Greenspan SI. Infant regulation of the vagal "brake" predicts child behavior problems: a psychobiological model of social behavior. Dev Psychobiol. 1996;29(8):697-712.

66. Rossi P, Andriesse Gl, Oey PL, Wieneke GH, Roelofs JM, Akkermans LM. Stomach distension increases efferent muscle sympathetic nerve activity and blood pressure in healthy humans. J Neurol Sci. 1998;161(2):148-55.

67. Fagius J, Karhuvaara S. Sympathetic activity and blood pressure increases with bladder distension in humans. Hypertension. 1989;14(5):511-7.

68. Kuczmarski RJ, Ogden CL, Guo SS, et al. 2000 CDC growth charts for the United States: Methods and development. National Center for Health Statistics. Vital Health Stat 11(246). 2002.

69. Barlow S, Committee E. Expert committee recommendations regarding the prevention, assessment, and treatment of child and adolescent overweight and obesity: Summary report. Pediatrics. 2007;120:S164-92.

70. Callaway C, Chumlea W, Bouchard C, Himes J, Lohman T, Martin A, Mitchell C, Mueller W, Roche A, Seefeldt V. Circumferences. In: Lohman T, Roche A, Martorell R, editors. Anthropometric standardization reference manual. Champaign: Human Kinetics Books; 1988.

71. Fields DA, Goran MI, McCrory MA. Body-composition assessment via airdisplacement plethysmography in adults and children: a review. Am J Clin Nutr. 2002;75(3):453-67.

72. Ginde SR, Geliebter A, Rubiano F, Silva AM, Wang J, Heshka S, Heymsfield SB. Air displacement plethysmography: validation in overweight and obese subjects. Obes Res. 2005;13(7):1232-7.

73. National High Blood Pressure Education P. The seventh report of the joint national committee on prevention, detection, evaluation, and treatment of high blood pressure. Bethesda: National Heart, Lung, and Blood Institute (US); 2004.

74. ACSM. Guidelines for exercise testing and prescription. Baltimore: Lippincott Williams \& Wilkins; 2010.

75. Borg GA. Psychophysical bases of perceived exertion. Med Sci Sports Exerc. 1982;14(5):377-81.

76. Malik M, Kautzner J, Hnatkova K, Camm AJ. Identification of electrocardiographic patterns. Pacing Clin Electrophysiol. 1996;19(2):245-51.

77. Blanton CA, Moshfegh AJ, Baer DJ, Kretsch MJ. The USDA Automated Multiple-Pass Method accurately estimates group total energy and nutrient intake. J Nutr. 2006;136(10):2594-9.

78. Moshfegh AJ, Rhodes DG, Baer DJ, Murayi T, Clemens JC, Rumpler WV, Paul DR, Sebastian RS, Kuczynski KJ, Ingwersen LA, et al. The US Department of Agriculture Automated Multiple-Pass Method reduces bias in the collection of energy intakes. Am J Clin Nutr. 2008;88(2):324-32.

79. Guenther PM, Casavale KO, Reedy J, Kirkpatrick SI, Hiza HA, Kuczynski KJ, Kahle LL, Krebs-Smith SM. Update of the healthy eating index: HEl-2010. J Acad Nutr Diet. 2013;113(4):569-80.

80. Wiltheiss GA, Lovelady CA, West DG, Brouwer RJ, Krause KM, Ostbye T. Diet quality and weight change among overweight and obese postpartum women enrolled in a behavioral intervention program. J Acad Nutr Diet. 2013;113(1):54-62.

81. Chinapaw MJ, de Niet M, Verloigne M, De Bourdeaudhuij I, Brug J, Altenburg TM. From sedentary time to sedentary patterns: accelerometer data reduction decisions in youth. PLoS One. 2014;9(11):e111205.

82. Taylor RW, Williams SM, Farmer VL, Taylor BJ. The stability of sleep patterns in children 3 to 7 years of age. J Pediatr. 2015;166(3):697-702.e691.

83. Tudor-Locke C, Barreira TV, Schuna JM, Jr., Mire EF, Chaput JP, Fogelholm M, Hu G, Kuriyan R, Kurpad A, Lambert EV, et al. Improving wear time compliance with a 24-hour waist-worn accelerometer protocol in the International Study of Childhood Obesity, Lifestyle and the Environment (ISCOLE). Int J Behav Nutr Phys Act. 2015;12:11.

84. Herrmann SD, Barreira TV, Kang M, Ainsworth BE. Impact of accelerometer wear time on physical activity data: a NHANES semisimulation data approach. Br J Sports Med. 2014;48(3):278-82.

85. Evenson KR, Catellier DJ, Gill K, Ondrak KS, McMurray RG. Calibration of two objective measures of physical activity for children. J Sports Sci. 2008;26(14): 1557-65.
86. Trost SG, Loprinzi PD, Moore R, Pfeiffer KA. Comparison of accelerometer cut points for predicting activity intensity in youth. Med Sci Sports Exerc. 2011;43(7):1360-8.

87. Evans GW, Fuller-Rowell TE, Doan SN. Childhood cumulative risk and obesity: The mediating role of self-regulatory ability. Pediatrics. 2012;129(1):e68-73.

88. Matthews KA, Gallo LC. Psychological perspectives on pathways linking socioeconomic status and physical health. Annu Rev Psychol. 2011;62:501-30.

89. Appleton AA, Buka SL, McCormick MC, Koenen KC, Loucks EB, Kubzansky LD. The association between childhood emotional functioning and adulthood inflammation is modified by early-life socioeconomic status. Health Psychol. 2012;31(4):413-22.

90. Danese A, Moffitt TE, Harrington H, Milne BJ, Polanczyk G, Pariante CM, Poulton R, Caspi A. Adverse childhood experiences and adult risk factors for age-related disease: Depression, inflammation, and clustering of metabolic risk markers. Arch Pediatr Adolesc Med. 2009;163(12):1135-43.

91. Doyle O, Harmon CP, Heckman JJ, Tremblay RE. Investing in early human development: Timing and economic efficiency. Econ Hum Biol. 2009;7(1):1-6.

\section{Submit your next manuscript to BioMed Central and we will help you at every step:}

- We accept pre-submission inquiries

- Our selector tool helps you to find the most relevant journal

- We provide round the clock customer support

- Convenient online submission

- Thorough peer review

- Inclusion in PubMed and all major indexing services

- Maximum visibility for your research

Submit your manuscript at www.biomedcentral.com/submit
C Biomed Central 